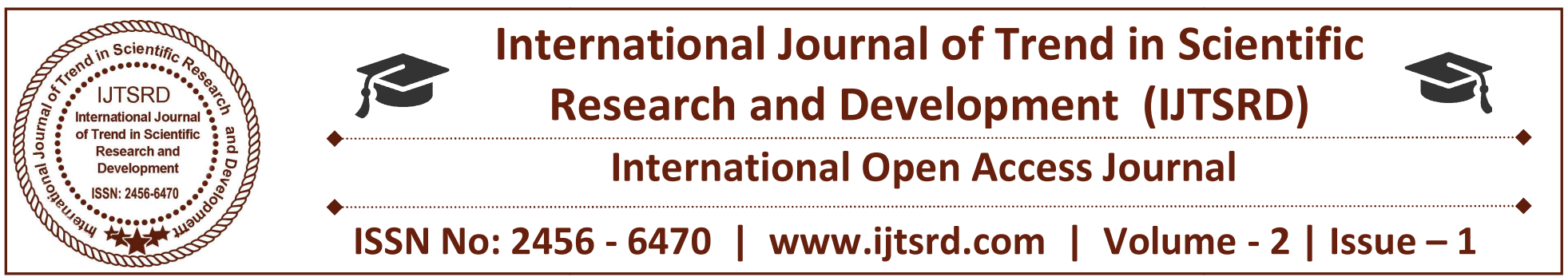

\title{
Antioxident Activity of Greenly Synthesized Anhydride
}

\author{
Yadav Hanuman Singh \\ Dr. Ira Nimdeokar Research Center for Chemistry, \\ HislopCollege, Nagpur, 440001, India
}

\author{
Gani Saba \\ Dr. Ambedkar College, Deekshabhoomi, \\ Nagpur, 440001, India
}

\begin{abstract}
One pot synthesis of acid esters by Stobbe condensation of alkylidene / arylidene succinates and aldehydes or ketones, their subsequent hydrolysis to diacids has reported. The Stobbe condensation of various aromatic aldehydes or ketones with dimethyl succinate gives different types of cyclized products through green approach. The improved yields of Fulgenic acid and its an hydride have observed by the green approach method as compared with other classical methods employed so far. The antioxidant activity of anhydride compounds have done by using DPPH.
\end{abstract}

Keywords: Green synthesis, Hexamethylenetetramine, Stobbe condensation, aryl aldehydes \& ketones and their products

\section{Introduction:}

The earlier classical method for the formation of Fulgenic acid and their anhydride forms ${ }^{\mathbf{1}, 2}$ are more time consuming and involved use of hazardous solvents like benzene, ether etc. and hence and not eco-friendly. Most of these solvents used for Fulgenic acid synthesis are inflammable, corrosive and have reported to be toxic and carcinogenic to exposed beings.

The present work describes an eco friendly one pot synthesis method for Stobbe condensation with minimum use of solvents. In contrast to the extensive use of solvent and hazardous chemicals used in previous methods ${ }^{3}$; currently studies. The green method requires fewer amounts of dry solid reagents, for the formation of acid esters ${ }^{4}$. Moreover, the solvent free condition improves the yield and heat energy consumption by the reaction is also averted.

Stobbe condensation under solvent free condition using Hexamethylenetetramine has done with dimethyl succinate and aromatic, aliphatic aldehyde and ketone forms acid- esters, which on saponification yielded the corresponding diacids ${ }^{5}$.Organic photochromic compounds such as Fulgenic acids are potential candidates for application in erasable opticalinformation media ${ }^{6}$. This green approach not only increases the product's yield, but also maintains and raises its photochromic strength. The Fulgidesi.e. anhydrides (cyclized forms) are the promising materials in optical memory devices, optical switches and sensors, especially dyes and inks. These are representative class of photochromic organic ${ }^{7,8}$, ${ }^{9}$ molecules which exhibits several interesting properties for diverse applications in fields such as data storage or high resolution spectroscopy.

The anhydride products are prepared by cyclisation of dicondensationdiacids by using silica and perchloric acid.

The antioxidant is a molecule that inhibits oxidation of biomolecule. Oxidation is a chemical reaction that can produce free radicals leading to chain reactions that may damage cells and initiates diseased condition. The term antioxidant mainly used for two different groups of substances: industrial chemicals which are added to products to prevent oxidation and natural chemicals found in food and body tissue which are said to have beneficial health effects ${ }^{\mathbf{1 0}}$.Antioxidants are classified into two broad divisions, depending on whether they are soluble in 
water (hydrophilic) or in lipids (lipophilic).In general, water soluble antioxidents reacts with oxidents in the cells cytosol and the blood plasma, while lipid soluble antioxidents protects cell membrane from lipid peroxidation ${ }^{11}$. In present study, we also determined the solubility property of Fulgenic acid esters. The different antioxidents are present at a wide range of concentration in body fluids and tissues.

\section{Materials and Methods:}

\subsection{Reagents}

The following reagents have used for experiments -

Dimethyl succinate, Hexamethylenetetramine, benzophenone, p-chlorobenzophenone, Butanone, Furfural, anhydrous methanol, ethylene dichloride, conc. sulfuric acid, 8\% alcoholic potassium hydroxide, Acetophenone, Bezaldehyde, Acetonehave used as raw materials. Benzene, Petroleum ether, nHexane have used for double solvent recrystallization of the obtained product. All the above solvents were purified by the reported procedures ${ }^{\mathbf{1 2}}$.All other chemicals used are of high analytical grade.

\subsection{Instrumentation:-}

The infrared spectra have obtained on a BrukerAVANCE 520 Fourier transform Infrared spectrometer using $\mathrm{KBr}$ pellets from SAIF Punjab University Chandigarh, India. High resolution ${ }^{1} \mathrm{H}-$ NMR spectra have recorded on a BrukerAvance II $400 \mathrm{MHz}$ spectrometer in $\mathrm{D}_{2} \mathrm{O}$ with TMS as an internal standard. Melting points have measured on a digital Electrothermal 9100 Melting Point Apparatus and reported without correction. Ultra violet and Visible spectra have measured for a $10^{-4} \mathrm{M}$ in Toluene solution. The $\mathrm{pH}$-metric titrations have conducted in aqueousethanol (50:50, v/v) on an automatic recording ECIL pH-meter (Model $\mathrm{pH}$ 821) having a glass-calomel electrode assembly. Molecular weights of the acidic products have determined by titrimetric method as their equivalent weights. The general pro cedure for Stobbe condensation and saponification of Stobbe condensation products have similar to those described earlier. These general procedures for Stobbe condensation have modified by using green method ${ }^{13}$, 14.

\subsection{General experimental procedure (Material synthesis)}

A mixture of dimethyl succinate $(9.0 \mathrm{~g}, 0.09$ mole $)$ and aldehydes or ketones have added dropwise to a suspension of Hexamethylenetetramine(12.6 g,0.09 mole).The reaction mixture ground in mortar and pestle for 10 minutes and allowed to stand for another 20 minutes. Then $3 \mathrm{~N} \mathrm{HCl}$ has added in small amounts. Alcohol has distilled off under reduced pressure and reaction mixture has extracted with ether at room temperature. Acidic substances have separated by using $10 \% \quad \mathrm{Na}_{2} \mathrm{CO}_{3}$. On further acidification, finally it gives acid ester which has again recrystallized with n-Hexane /Benzene petroleum ether. Further on esterification, with anhydrous $\mathrm{CH}_{3} \mathrm{OH}$, ethylene dichloride and conc. $\mathrm{H}_{2} \mathrm{SO}_{4}$ at room temperature it gives diester .Once again the dieter has mixed with aldehydes or ketones and Hexamethylenetetramine, the same procedure repeated and recrystallization has done with $\mathrm{n}$-Hexane /Benzene, petroleumether which gives $2^{\text {nd }}$ acid ester. Finally the obtained $2^{\text {nd }}$ acid ester has saponified with alcoholic $\mathrm{KOH}$ at room temperature for 1 hour and followed by acidification and recrystallization which would give a solid crystalline natured $\operatorname{diacids}(\mathbf{2 a}, \mathbf{2 b}$, 2c, 2d).

Further these diacids undergo cyclisation in presence of silica and perchloric acid (1:1) to give anhydrides(3a, 3b, 3c, 3d).

\section{Results and Discussions:}

In this research article, Fulgides have prepared via Stobbe condensation using hexamethylenetetramine through green context. Further these diacids undergo cyclisation in presence of silica and perchloric acid (1:1) to give anhydrides.

Stobbe condensation generally involves the use of metal alkoxideas a catalyst in refluxing alcohol, particularly, butanol ${ }^{15}$. On the other hand, instead of butanol, in this research paper Hexamethylenetetramine, has taken for the reaction. The advantages are short reaction time, good yield, less by-products. 


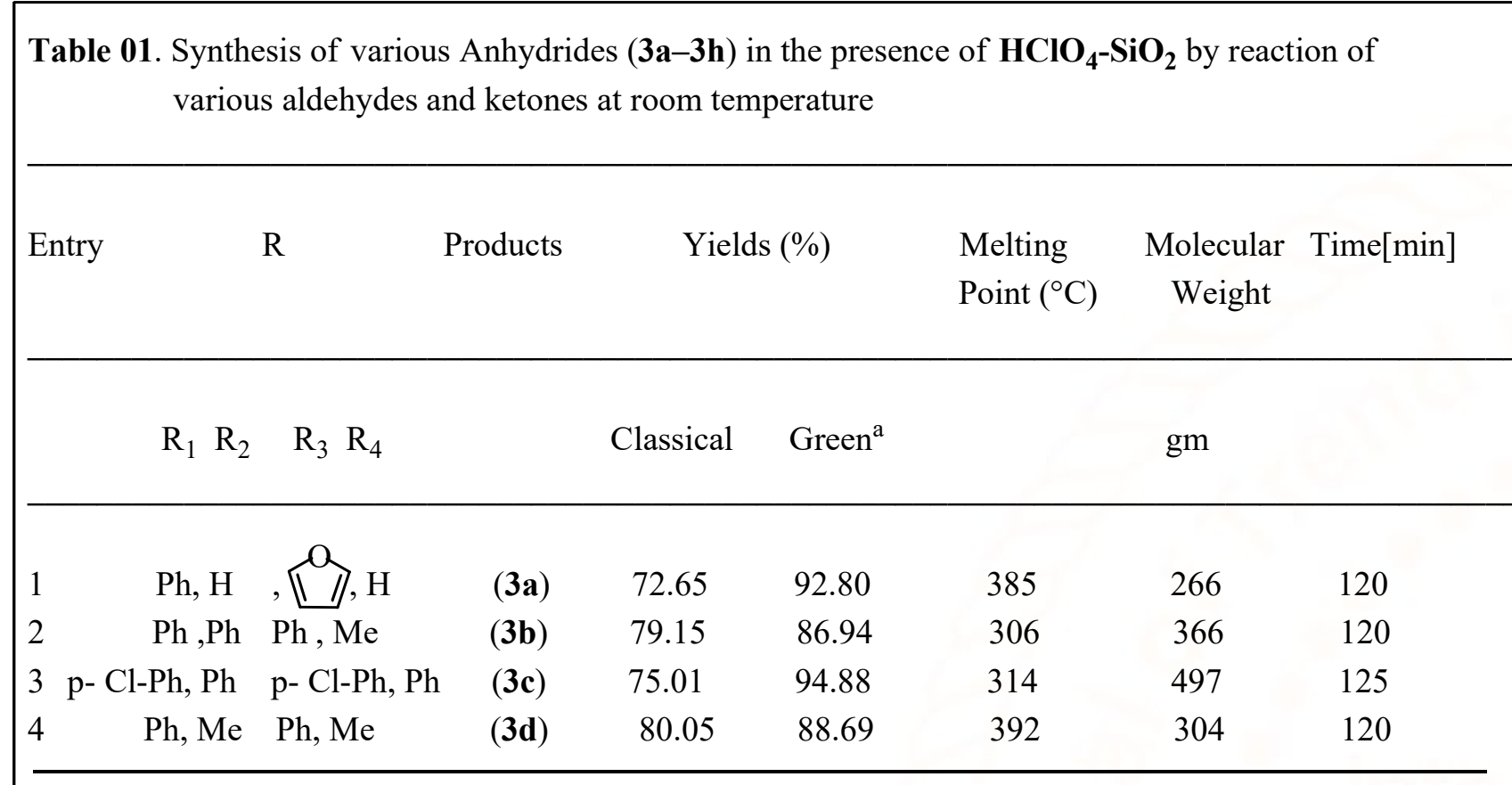

Green $^{\mathrm{a}}$ refer to the pure isolated products during green synthesis.

\begin{tabular}{lc}
\hline Compounds Identity & Ascorbic Acid Equivalent $(\mu \mathrm{g})$ \\
\hline 3a & 15.77 \\
3b & 14.72 \\
3c & 5.41 \\
3d & 9.10
\end{tabular}

Table 2. Antioxidant activity of Fulgides in terms of ascorbic acid equivalent

The Fulgides (3a, 3b, 3c, 3d) synthesized using current method is of high purity compared with classical synthesis. The synthesized Fulgides have specific melting and boiling point, NMR peak values. In previous synthetic methods, tremendous heat has used, which leads impurediacids with less percentage yield $^{16}$.

The anhydride(3E,4E)-3-benzylidene-4-(furan-2ylmethylene)dihydrofuran-2,5-dione(3a)exhibited a molecular formula $\mathrm{C}_{16} \mathrm{H}_{10} \mathrm{O}_{4}$ showed highest antioxidant activity, due to presence of phenyl and furfural group. (Figure 1)

The anhydride (E)-3-(diphenylmethylene)-4-(1phenylethylidene) dihydrofuran-2, 5-dione( $3 b$ ) having molecular formula $\mathrm{C}_{25} \mathrm{H}_{18} \mathrm{O}_{3}$ also showed second highest antioxidant activity. Due to presence of onemethylits activity gets lower down.(Figure1).

The anhydride (3Z,4E)-3 , 4-bis ((4-chlorophenyl) (phenyl) methylene) dihydrofuran-2,5-dione (3c) having molecular formula $\mathrm{C}_{30} \mathrm{H}_{18} \mathrm{Cl}_{2} \mathrm{O}_{3}$ also showed antioxidant activity, but due to presence of halogen i.e. electron withdrawing group, its value decreses. (Figure1).

The anhydride (3Z,4Z)-3, 4-bis (1phenylethylidene)dihydrofuran-2,5-dione(3d) having molecular formula $\mathrm{C}_{20} \mathrm{H}_{16} \mathrm{O}_{3}$ showed less antioxidant activity due to presence of two methyl groups. (Figure1). 


\subsection{Reaction Schemes of Experimental Work}

The synthesis of different substitutedFulgenicacids and their cyclized products have possible by
stepwiseStobbedicondensation with different aldehydes and ketones through green approach which are given as below.

Scheme 1

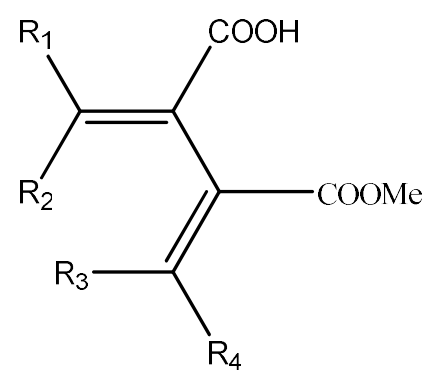

(1)

a) $\mathrm{R} 1, \mathrm{R} 2=\mathrm{Ph}, \mathrm{H} \quad$; $\mathrm{R} 3, \mathrm{R} 4=\mathrm{C}_{5} \mathrm{H}_{6} \mathrm{O}, \mathrm{H}$ b) R1, R2 $=\mathrm{Ph}, \mathrm{Ph} \quad$; R3, R4 $=\mathrm{Ph}, \mathrm{Me}$ c) $\mathrm{R} 1, \mathrm{R} 2=\mathrm{p}-\mathrm{Cl}-\mathrm{Ph}, \mathrm{Ph} ; \mathrm{R} 3, \mathrm{R} 4=\mathrm{p}-\mathrm{Cl}-\mathrm{Ph}, \mathrm{Ph}$ d) $\mathrm{R} 1, \mathrm{R} 2=\mathrm{Ph}, \mathrm{Me} \quad$; $\mathrm{R} 3, \mathrm{R} 4=\mathrm{Ph}, \mathrm{Me}$

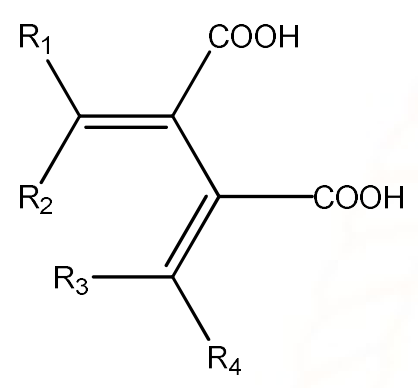

(2)

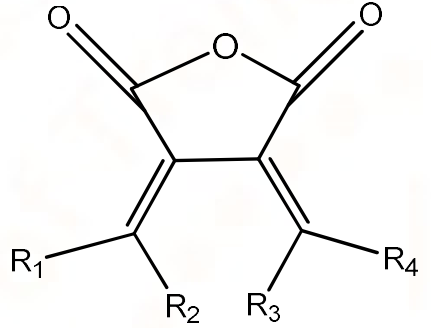

(3) $\begin{array}{ll}\text { a) } \mathrm{R} 1, \mathrm{R} 2=\mathrm{Ph}, \mathrm{H} & ; \mathrm{R} 3, \mathrm{R} 4=\mathrm{C}_{5} \mathrm{H}_{6} \mathrm{O}, \mathrm{H} \\ \text { b) } \mathrm{R} 1, \mathrm{R} 2=\mathrm{Ph}, \mathrm{Ph} & ; \mathrm{R} 3, \mathrm{R} 4=\mathrm{Ph}, \mathrm{Me} \\ \text { c) } \mathrm{R} 1, \mathrm{R} 2=\mathrm{p}-\mathrm{Cl}-\mathrm{Ph}, \mathrm{Ph} & ; \mathrm{R} 3, \mathrm{R} 4=\mathrm{p}-\mathrm{Cl}-\mathrm{Ph}, \mathrm{Ph}\end{array}$

$\begin{array}{ll}\text { d) } \mathrm{R} 1, \mathrm{R} 2=\mathrm{Ph}, \mathrm{Me} & ; \mathrm{R} 3, \mathrm{R} 4=\mathrm{Ph}, \mathrm{Me}\end{array}$ a) $\mathrm{R} 1, \mathrm{R} 2=\mathrm{Ph}, \mathrm{H} \quad$; $\mathrm{R} 3, \mathrm{R} 4=\mathrm{C}_{5} \mathrm{H}_{6} \mathrm{O}, \mathrm{H}$ b) $\mathrm{R} 1, \mathrm{R} 2=\mathrm{Ph}, \mathrm{Ph} \quad$ : R3, R4 $=\mathrm{Ph}, \mathrm{Me}$ c) R1,R2 = p- Cl-Ph, Ph ; R3,R4=p-Cl-Ph. Ph d) $\mathrm{R} 1, \mathrm{R} 2=\mathrm{Ph}, \mathrm{Me} \quad$; R3, $\mathrm{R} 4=\mathrm{Ph}, \mathrm{Me}$

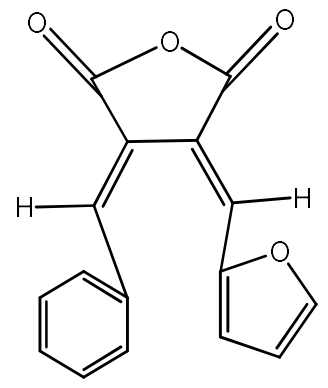

(3a)

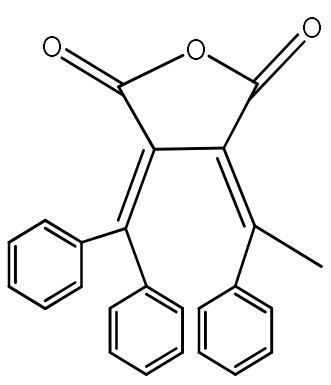

(3b)

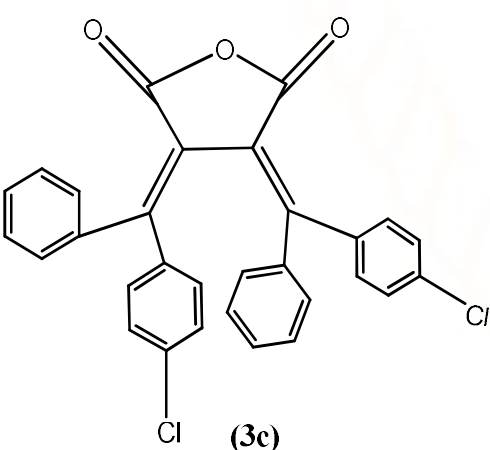

(3c)<smiles>CC(=C1C(=O)OC(=O)C1=C(C)c1ccccc1)c1ccccc1</smiles>

structures of Anhydrides (cyclised products) 


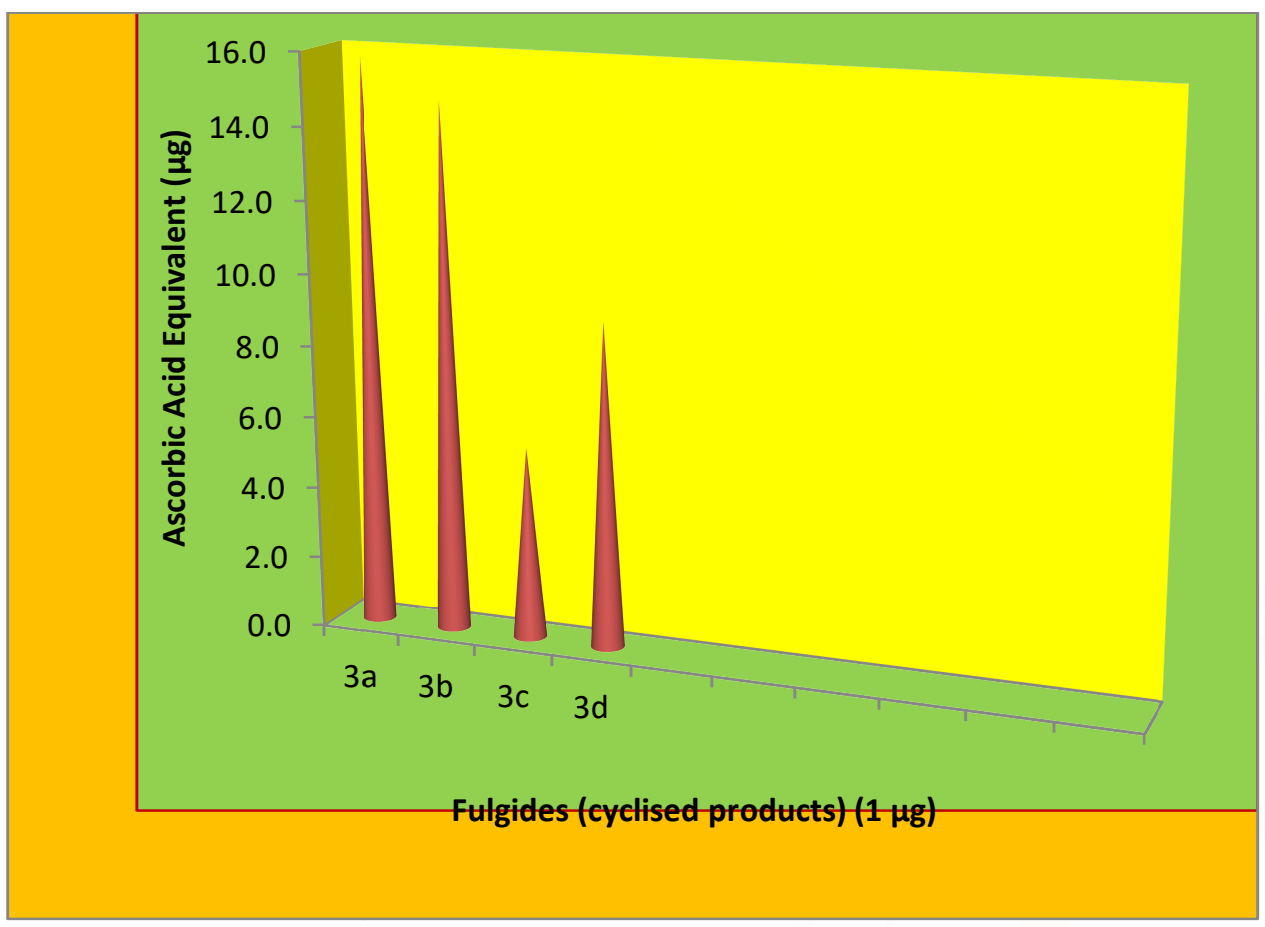

Figure no. 1Antioxidant activity of Fulgides in terms of ascorbic acid equivalent

\section{Conclusion:}

The greener chemical reaction strategy managed to synthesize Fulgenic acid (2a, 2b, 2c, 2d) successfully by simple and efficient means with improved yield. The solvent free Stobbe condensation of aromatic aldehydes and aliphatic, aromatic ketones with dimethyl succinate at room temperature occurred smoothly to give substituted acid esters which on further saponification gives diacid. These diacids undergo cyclisation in presence of silica and perchloric acid (1:1) to give anhydrides. This methodology brought down not only the reaction time but also the uses of hazardous organic solvents (as possible $)^{17,18}$. The prepared anhydrides (3a, 3b, 3c, 3d) can also be used in the preparation of photosensitive glasses, photosensitive toys and other instruments, Optical data recording like Compact Disc, preparation of photosensitive inks for security purpose, and variable density filters.

\section{Acknowledgement:}

The authors are grateful to SAIF Chandigarh, for IR, MASS and NMR spectra and Principal, Hislop College, Nagpur, India for providing research facility and Dr. Saba Gani for her help \& interest.
The authors are also grateful to NEERI, Nagpur, for antioxidant activity of anhydride compounds.

\section{REFERENCES}

1) Amarowicza R., Peggb R.B., RahimiMoghaddamc B., BarldJ. A.; Food Chemistry, 84, (March 2004), (4), 551-562.

2) Shahidi F., Zhong Y.; Journal of Functional Foods , 18, (2015), (6), 757- 781.

3) Rea R., Pellegrinia N., Proteggentea A., Pannalaa A., Yanga M.; Free Radical Biology and Medicine; 26, (May 2004), (9-10), 1231-1237.

4) Wei Z. h. and Shiow Y. W. ; J. Agric. Food Chem., 49,(2001), (11), 5165-5170.

5) Gil M.I.,Tomás-Barberán F.A., Hess-Pierce B., Holcroft D.M., Kader A.A.; J Agric. Food Chem., 48, (2000 Oct), (10), 4581-4589.

6) Adom K.K., Liu R. H.; J. Agric. Food Chem., 50, (2008 Oct) (21):6182-6187.

7) Saeed N., Khan M. R, Shabbir M.; journal of the International Society for Complementary Medicine Research (ISCMR) 56, (2012),(5), 125131.

8) Maqsood S., Singh P., Samoon M.H., Balange A.K..; Inter Aqua Res., 2, (2010), (4), 77-85. 
9) Zengin G., Cakmak Y.S., Guler G.O., Aktumsek A.; Rec Nat Prod. 5 :( 2011), 123-132.

10) Vongtau H.O., Abbah J., Chindo B.A., Mosugu O., Salawu A.O., Kwanashie H.O., Gamaniel

K.S.; J Pharm Biol., 43, (2005),(6),113-120.

11) Oluyemi K.A., Okwuonu U.C., Baxter D.G., Oyesola T.O.; Int J Morphol.,25, (2009), (5) 609-

614.

12) Halliwell B., Gutteridge J.M.; FEBS. Lett.,128, (2001),(4),347-352.

13) Gulcin I.; an overview. Arch Toxicol., 86 (2012),(5),345-391.

14) Gocer H., Gulcin I.; - Global Approaches to Their Role in Nutrition and Health. (2012).

15) Nunes P.X., Silva S.F., Guedes R.J., Almeida S.; Int J Food Sci Nutr., 62 (2011), (63) 821-825.

16) Djeridane A., Yousfi M., Nadjemi B., Boutassouna D., Stocker P., Vidal N. ; Food Chem., 654-660.

17) Wannes W.A., Mhamdi B., Sriti J., Jemia M.B., Ouchikh O., Hamdaoui G., Kchouk M.E., Marzouk B.; Food ChemToxicol., 48, (2010), (7), 1362-1370.

18) Valko M., Leibfritz D., Moncola J., Cronin M., Mazura M., Telser J.; Int J Biochem Cell Biol., 39, (2007), (1), 44-84 